\title{
Influence of climate and anthropogenous activity on the terrigenous sedimentation dynamics of the Sea of Azov in the second part of the $\mathrm{XX}^{\text {th }}$ century
}

\author{
S. V. Berdnikov \& V. V. Sorokina \\ Southern Scientific Center of the Russian Academy of Sciences, Russia
}

\begin{abstract}
Spatiotemporal peculiarities of terrigenous sedimentation in the second part of the $\mathrm{XX}^{\text {th }}$ century are analyzed on the basis of balance calculations with the application of a spatially detailed mathematical model of transport and sedimentation of suspended matter adjusted for the Sea of Azov. The setup and calibration of this model are described and an interpretation of the results is carried out.

According to climatic fluctuation and anthropogenous activity, four periods of terrigenous sedimentation in the second part of the $\mathrm{XX}^{\text {th }}$ century are determined. The schemes of deposition and erosion sediment matter are made. The general tendency of a decrease in terrigenous matter accumulation and an increase in the squares of negative balance of terrigenous matter is caused by a 2.5 -fold reduction of volume in the transported land matter. In the study period, the intensity of sedimentation decreased from 1000 to $400 \mathrm{~g} / \mathrm{m}^{2}$ per year.
\end{abstract}

Keywords: terrigenous sedimentation, mathematical modelling, the Sea of Azov.

\section{Introduction}

The Sea of Azov is a small and shallow sea in the southern part of European Russia (the area of the water surface is $38000 \mathrm{~km}^{2}$, and the maximum depth is 13,5m), fig. 1. More than 10 million people live in the Azov basin. The unique complex of natural conditions determines the peculiarity of the process of modern sedimentation: the extreme dynamics and great spatial changeability. 
In the second part of the $20^{\text {th }}$ century a significant transformation of the terrigenous matter input to the Sea of Azov took place. The transformation was caused by climate impact, as well as by anthropogenic influence on conditions of solid runoff formation of river basins.

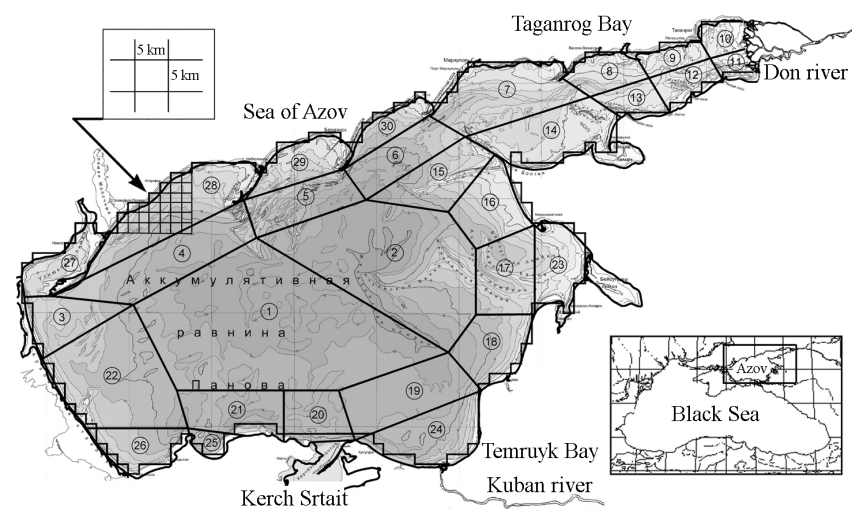

Figure 1: The Sea of Azov. The scheme of net approach joined up to compartmental model of water exchange.

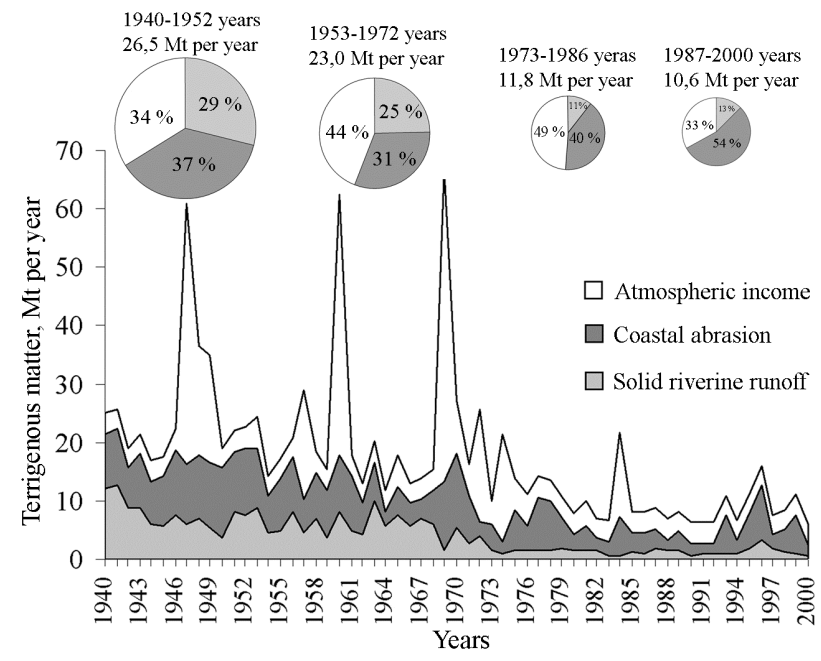

Figure 2: $\quad$ Entry of terriogenous material to the Sea of Azov.

In the period 1940-2000 under the circumstances of reduction of sedimentary materials input to the sea, the volume of river runoff and eolian income decreased, while the volume of coasts' abrasion materials increased, fig. 2. The considered period of research can be split into four intervals. Every part has its own combination of the way of sedimentation circumstances 
The purpose of this paper is to make a reconstruction of terrigenous sedimentogeneses processes on the basis of detailed analysis of dynamics of sediment entry volume with the river runoff during abrasion, and from the atmosphere in 1940-2000, then applying the method of mathematical modelling.

\section{Research materials and methods}

A modified multi-compartmental model of transfer and sedimentation of suspended matters in the Sea of Azov that is introduced in the paper [1] for the calculation of accumulation of technogenous micro-particles in bottom sediments, transferred with the river flow and from the atmosphere, was applied. A compartmental approach for calculation of suspended matter transfer by water masses is combined with a net approach for a more precise calculation of impact of relief peculiarities of the bottom on bottom sediments roiling fig. 1 . The assessment of the thickness of a layer of scour sediment is based on method [2] that proposes an equation for calculation of influence of roughness and currents on the distribution of suspended materials in water thickness depending on the size of the particles and depth of the sea area, fig. 3 .

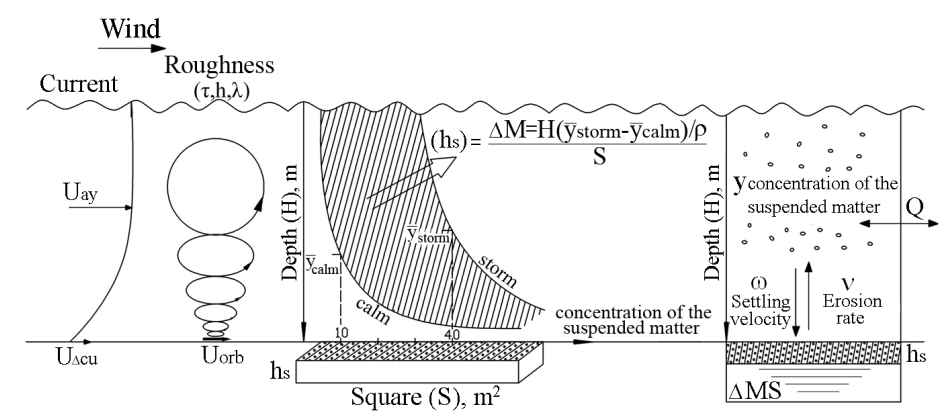

Figure 3: Model scheme of suspended matters sedimentation and roiling of bottom sediments in shallow water body. $U_{\Delta \mathrm{cu}}$ is the drainage and drift components of the current velocity near the bottom; $\mathrm{U}_{\Delta \text { orb }}$ is the horizontal component of the orbital velocity near the bottom; $\mathrm{U}_{\mathrm{av}}$ is the averaged in depth current velocity; $\tau, \mathrm{h}, \lambda$ are the period $(\mathrm{s})$, height $(\mathrm{m})$ and length $(\mathrm{m})$ of the wave, respectively; $\omega$ is the sediment's settling velocity $\left(\mathrm{m} \mathrm{s}^{-1}\right) ; v$ is the erosion rate $\left(\mathrm{g} \mathrm{m}^{-2} \mathrm{~s}^{-1}\right)$; $\mathrm{Y}$ is the concentration of suspended matter in water $\left(\mathrm{g} \mathrm{m}^{-3}\right) ; \mathrm{h}_{\mathrm{s}}$ is the thickness of the layer of bottom sediments which particles may be suspended into water ( $\mathrm{mm}$ ), calculated depending on the depth; $\rho$ is the density of the suspended matter $\left(\mathrm{g} \mathrm{cm}^{-3}\right)$; Q is aggregate of processes that determine the entry of suspended matters to the compartment and exchange of the compartment to the other one; $\Delta \mathrm{M}$ is the total weight of roiled particles that are involved in the exchange processes between the bottom and the water thickness $\left(\mathrm{g} \mathrm{m}^{-2}\right)$. 
Solid runoff is concentrated in regions 10 and 11 (the Don River), and 24 and 18 (the Kuban River).

The entry of terrigenous materials from the atmosphere for the particles of different sizes is calculated on the basis of average intensity of aerosols fall-out to the aquatory of the sea itself and the Taganrog Bay when the sea is calm and in years with dust storms.

The entry of abrasion materials in the areas of the sea according to researches of abrasion coasts in the Sea of Azov for the last years is given in [3].

For every year of the researched period the schemes of the sediments entry, taking seasonality into account, were build.

Primary distribution of grain-sized types of sediments, the data of field observations and the map of grounds of the Sea of Azov in the late 1930's are used [4].

To assess the influence of the roughness on the roiling of bottom sediments the type fields of wave period and height for typical winds with velocity of more than $11 \mathrm{~ms}^{-1}$ taking into account their recurrence in different seasons, historical and modern data on frequency of storms registered of the coastal meteorological stations are used.

Calibration of the parameters of the mathematical model was carried out by comparison of calculated and observed content of mineral suspended matter in the Sea of Azov. While checking the adequacy of the model, the comparison of the pelite fraction in the upper layer of insoluble sediments based on the results of calculations and published schemes [5] for the same years was carried out. From the beginning of the 1940s sedimentation in the Sea of Azov has been characterized by the following, proved by the results of calculations, tendencies: a) reduction of the area of clayey slits (pelite $>70 \%$ ), mainly in the Taganrog Bay, erosion of fine fractions of sediments from transit areas and their accumulation in the central, deepest part of the sea; b) broadening of areas containing $0-30 \%$ of pelite fractions in sediments, especially in the eastern part of the sea itself.

The main causes of such tendencies are significant reduction of volume of entering terrigenous material to the Sea of Azov, as well as changing input of some sources. At the same time, the hydrochemical peculiarities in the shallow Sea determine the distribution of material on the area of the water body, and contribute to mobilization transport of fine-grained material to hydrodynamically more stable areas.

\section{Results of calculation and discussion}

The interannual variability of terrigenous material volume and erosion of bottom sediments involved in sedimentation are characterized by the following patterns. The overall tendency to the decrease of sedimentation of terrigenous material is observed. Such tendency is conditioned by reduction of volumes of material entering from the land by more than 2.5 times, fig. 2. Against this, several peaks of sedimentation that correspond to the years with avalanche-like input of particles to the sea are distinguished, mainly by eolian factor. Until mid 1970's at the time of maximum entry of sediments, the areas and volume of erodible 
bottom sediments were reduced, and from the beginning of mid 1980's in the flow of sediment matter the input of particles that were formed by erosion of bottom sediments and transported by currencies to the areas of accumulation, has been increasing.

In the 1980-1990's, due to climate change, the tendency of increased hydrodynamical activity (decrease of average year wind velocity, frequencies of situations with maximum velocity) was observed. Naturally, this fact should have decreased the erosion intensity progress and velocity of erosion that is proved by calculations in the last 20 years of the $20^{\text {th }}$ century. Moreover, the significant decrease of volume of entry from the land material determines the enlarging of the areas with a negative balance of terrigenous sediments.

On the whole, the intensity of sedimentation has reduced from 1000 to 400 $\mathrm{g} / \mathrm{m}^{2} /$ per year. Because of hydrodynamic activity, lowering the speed of erosion of bottom sediments (from 600 to $200 \mathrm{~g} / \mathrm{m}^{2} /$ per year) has decreased too, but due to defecate of terrigenous matters the areas that are under the influence of bottom erosion have enlarged.

According to the results of calculations the following regional features of terrigenous sedimentation, which are determined by the overall decrease of entry of sediments, spatial distribution of basic sources, patterns of climate processes, and oceanographic features of the Sea of Azov, are revealed.

The period of 1940-1952 was characterized by high speed sedimentation $\left(1000-1500 \mathrm{~g} / \mathrm{m}^{2} /\right.$ per year) especially in the areas of terrigenous matters entry (Taganrog Bay, Temryuk Bay and in the northern bays of the sea), fig. 4. The percentage of areas with the highest speed of sedimentation is as follows: in the Taganrog Bay it is about $60 \%$, and in the sea itself is more than $10 \%$. The areas with the lowest speeds of material sedimentation $\left(0-500 \mathrm{~g} / \mathrm{m}^{2} / \mathrm{per}\right.$ year $)$, and often, of erosion of bottom sediments are eastern (areas 16 and 17) and western (areas 3, partially 4, 22, 26, 28) parts of the sea itself. In the central part of the sea $($ areas 1,2$)$ the intensity of sedimentation is about $600 \mathrm{~g} / \mathrm{m}^{2} /$ per year.

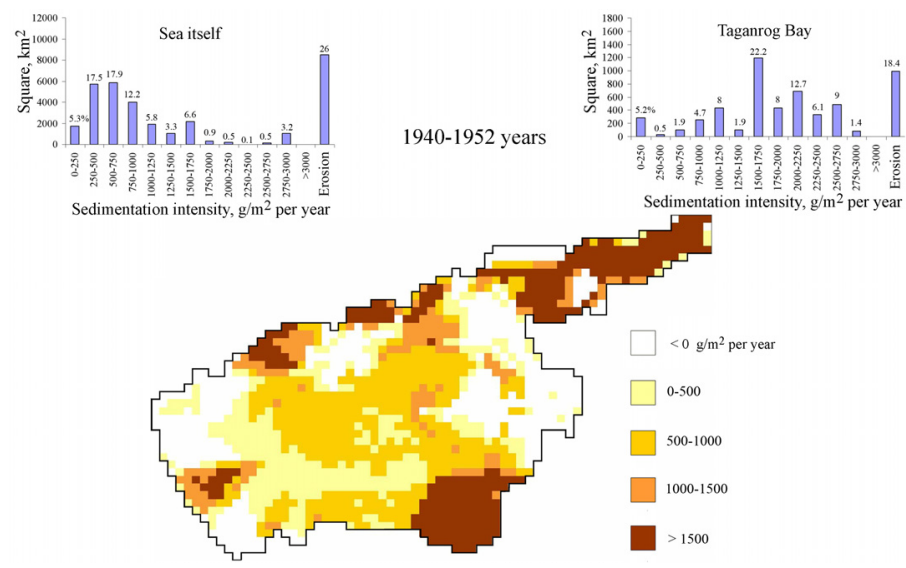

Figure 4: Spatial features of sedimentation intensity, 1940-1952. 
In 1953-1972 the areas with maximum speed of sedimentation (more than $2000 \mathrm{~g} / \mathrm{m}^{2} /$ per year) in the Taganrog Bay and in the sea itself decreased almost by 2 times, areas with an intensity of the sedimentation (from 1500 to 1000 $\mathrm{g} / \mathrm{m}^{2} /$ per year) increased.

The crucial changes in the process of sedimentogenesis happened in 19731986. That period was characterized by the decrease of entry of suspended matters by 4 times with the river runoff and reduction of frequency and strength of dust storms. The areas with low intensity of sedimentation (up to $500 \mathrm{~g} / \mathrm{m}^{2} / \mathrm{per}$ year) in the Taganrog Bay increased up to $30 \%$, and in the sea itself composed almost $60 \%$. The areas with average sedimentation intensity $\left(500-1000 \mathrm{~g} / \mathrm{m}^{2} / \mathrm{per}\right.$ year) has broadened in the Taganrog Bay up to $30 \%$ and has decreased in the sea itself to $14 \%$, and they are in the areas with maximum depth $(>13.5 \mathrm{M})$. The areas with high speed of sedimentation $\left(>1500 \mathrm{~g} / \mathrm{m}^{2} /\right.$ per year) have nearly disappeared.

In 1987-2000 on the background of development of abrasion processes of coastal zones that are under the influence of storms of western quarter and increase of solid river runoff of the Kuban River, the average speeds of sedimentation still continued to decrease. The areas with the speed of more than $1250 \mathrm{~g} / \mathrm{m}^{2} /$ per year in the Taganrog Bay and in the sea itself are nearly registered, fig. 5. The most intensive terrigenous sedimentation is in the areas characterized by the sources of transport of material and where the peculiarities of morphology of the bottom and hydrochemical activity are contributing to: the central part of the Taganrog Bay (areas 8, 13, partially 7, 14), in the Temryuk Bay and in the northern bays of the sea. In the central part of the sea the intensity of sedimentation is $300 \mathrm{~g} / \mathrm{m}^{2} /$ per year. The areas with the negative balance of terrigenous sediments in the Taganrog Bay and in the sea itself increased nearly up to $30 \%$ that was conditioned mainly by the deficit of terrigenous material than by hydrodynamical activity. The typical areas for the erosion could be the eastern and north-western part of the sea, and local areas of bays of the northern coast.

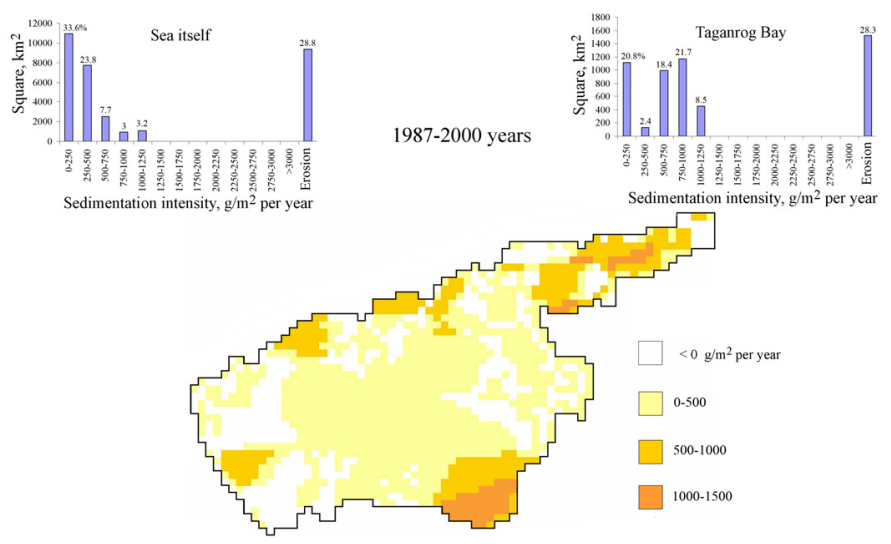

Figure 5: Spatial features of sedimentation intensity, 1987-2000, g/m $/ \mathrm{m}^{2} / \mathrm{per}$ year. 
In the used part of the balance the volume of material carried away to the Black Sea was $8-13 \%$, it basically contained particles of pelite size $(99 \%)$. The overall volume of carried away material decreased to 1.20 million tons in the last period from 2.57 million tons in the first period. But on the whole according to the results of calculations it is more than 1.0 million tons according to the paper [6].

According to the assessments, terrigenous sources provided with not less than $80 \%$ of sediments in the overall balance of sediment matters forms the bottom sediments of the Sea of Azov [5]. To conclude the velocity of sedimentogenesis it is necessary to carry out the analysis of the modern state of indigenous sources that provide the accumulation of biogenic sediment matter (organic matter and skeletal remains of phytoplankton and benthos), in particular according to definite changes that are typical of production processes in the sea (desalination, press of plankton predator mnemiopsis since 1989, introduction into benthos communities of such mollusks as Mytilaster, Mya, Abra, Anadara, significant decrease of sturgeons, main benthos eating fishes, etc.). The mud volcanism is the source of significant influence as well.

Revealed patterns of terrigenous sedimentation in the contemporary period can amend the carried out researches and formed scientific concepts.

In 1992-1998 the increase of content of $\mathrm{C}_{\text {org }}$ in bottom sediments by $30-50 \%$ comparing to 1971-1987 is noticed, linked to increase of primary production in the sea, and, accordingly, the fluxes of the solid matters to the bottom [7]. In this case, the cause of primary production growth was considered the introduction of Ctenophora into the Azov-Black Sea basin [8], and then reduced chemical load on the Sea of Azov. As the concentration of $\mathrm{C}_{\text {org }}$ in the bottom sediments is determined by the relation of accumulated volumes of terrigenous material and organic matter, the general decrease of intensity of terrigenous sedimentogenesis can be the cause of relative increase of $\mathrm{C}_{\text {org }}$ in sediments.

The broadening of areas, revealed during calculations, in which accumulation of terrigenous material does not compensate the processes of scour of bottom sediments, can intensify the processes of secondary pollution of water thickness by matters accumulated in bottom sediments in the previous periods. The problem has been noted during the reconstruction of pollution dynamics of the Sea of Azov with artificial radionuclides after the Chernobyl accident [9], and needs to be assessed for such kinds of contaminants as compounds of heavy metals and persistent pesticides.

\section{References}

[1] Berdnikov S. V., Ivlieva O.V., Prudnikova (Sorokina) V.V. Mathematical Modeling of Transport and Sedimentation of Technogenous Particles in the Sea of Azov. Oceanology. V.41. №6. pp. 805-814, 2001.

[2] Rzhanitsyn N.A. Suspension of Sediment with Turbulent Flow in Condition of Rough Sea. River Hydraulics and Hydrotechny. Ministry of Inland Water Transport Publishing. pp. 28-46, 1952. 
[3] Berdnikov S. V., Ivlieva O.V. Modern Velocities of Destruction of the Russian Coasts of the Sea of Azov. Geomorphology. №4. pp. 74-83, 2005.

[4] Hydrometeorological Reference Book of seas of USSR. The Sea of Azov. Editors-in-Chief Knipovich N.M., Bregman G.R. L.: Gidrometeoizdat. pp. 229-461, 1937.

[5] Khrustalev Yu. P. Patterns of Sedimentation in Closed Seas of Arid Zone. L.: Nauka. p. 261, 1989.

[6] Shnyukov E.F., Orlovsky G.N., Usenko V.P. et al Geology of the Sea of Azov. Kiev: Naukova Dumka. p. 247, 1974.

[7] Studenikina E.I., Mirzoyan Z.A., Safronova L.M. The Characteristic of the Sea of Azov Ecosystem under Circumstances of Change Natural and Anthropogenic Factors. Environment Protection in Oil and Gas Complex. № 9. pp. 67-70, 2006.

[8] Aleksandrova Z.V., Baskakova T.G., Romova M.G. Peculiarities of hydrochemical Conditions and Production of Primary organic matter in Ecosystem in Present Time. Ctenophora Mnemiopsis Leidyi (A. Agassiz) in the Sea of Azov and the Black Sea: Biology and Consequences of its Installation. Editor-in-Chief Volovik S.P. Rostov-on-Don: BKI. pp. 145$172,2000$.

[9] Matishov G.G., Gargopa Yu. M., Berdnikov S. V., Dzhenyuk S.L. Patterns of Ecosystem Processes in the Sea of Azov. M.: Nauka. p. 304, 2006. 